\title{
INVESTIGATION OF THE AERODYNAMIC FORCES OF A TRIANGULAR WIND TURBINE BLADE FOR THE LOW WIND SPEEDS
}

\author{
Tanasheva N.K. ${ }^{1}$, Tleubergenova A.Zh. ${ }^{1}$, Shaimerdenova K.M. ${ }^{1}$, \\ Minkov L.L. ${ }^{2}$, Uzbergenova S.Zh. ${ }^{3}$ \\ 1 E.A. Buketov Karaganda University, Karaganda, Kazakhstan, shymkent.a7@mail.ru \\ ${ }^{2}$ National Research Tomsk State University, Tomsk, Russia \\ ${ }^{3}$ Kokshetau University named after Sh. Ualikhanov, Kokshetau, Kazakhstan
}

\begin{abstract}
This article investigates the aerodynamic characteristics and finds the critical angle of attack of a triangular sail blade of a wind turbine for low wind speeds. For this purpose, a triangular sail blade of various parameters has been developed. The prototype is made of metal frame rods, the material of the triangular sail blade consists of a light and durable material (silk), one end of which is fixed to the top of the frame with a strong thread and support rods and bearing with an inner diameter of $8 \mathrm{~mm}$. A sail blade differs from other blades in that the sails are made with the ability to change the angle of attack using a movable thread. To determine the critical angle of attack, the aerodynamic forces of the sail blade were investigated at different angles of attack $0^{\circ} ; 15^{\circ} ; 30^{\circ} ; 45^{\circ}$, $60^{\circ} ; 75^{\circ} ; 90^{\circ}$. From the data analysis, it was found that the critical angle of attack is $15^{\circ}$, at which the value of the lift is maximum. Furthermore, at the critical angle of attack, the dependences of the lift and drag force on the air flow velocity were established, the value of which varied from 4 to $12 \mathrm{~m} / \mathrm{s}$.
\end{abstract}

Keywords: Sail, wind power plant, flow speed, aerodynamic force, wind tunnel T-1-M, angle of attack.

\section{Introduction}

The wind has been used to generate electricity since the 10s-20s of the twentieth century. Although, wind energy began to develop since the 90 s of the previous century by the 21 st century the development acquired a significant impetus and has now accelerated.

Today, wind turbines are one of the most affordable forms of energy production without the use of fossil fuels. Wind occurs due to uneven heating of the atmosphere surrounding the planet Earth, unevenness of the earth's surface, and air movement relative to the earth's surface, mainly in the horizontal direction. Therefore, the wind is found in all areas of the Earth. The wind generators' first prototype was windmills, which convert wind energy into mechanical energy. With the invention of electric machines, it was possible to convert wind energy into electrical energy.

Wind generators do not require additional costs after their installation if not taking into account the failure of power equipment and breakdowns in the mechanical links of the wind generator. Concerning the environmental aspect of wind energy, the annual installation of a 500 megawatt (MW) wind farm capable of generating 1.5 million MW of energy per hour will prevent emissions of 1.5 million tons of greenhouse gases, 12 thousand tons of sulfur oxide, 7.8 thousand tons of nitrogen oxide, 12.6 thousand tons of ash and 420 thousand tons of solid waste.

The average annual wind speed in $10 \%$ of the territory of Kazakhstan will be $6 \mathrm{~m} / \mathrm{s}$ and higher, which will contribute to the better development of wind energy in the future. Wind energy potential in Kazakhstan is about 1,820 billion $\mathrm{kWh}$ per year [1].

The climate in Kazakhstan is favorable for the construction of wind farms due to wind corridors with a wind speed of more than $5 \mathrm{~m} / \mathrm{s}$, which is necessary for the operation of wind turbines [2].

The main important part of the wind turbine is a blade. The blades of a wind generator are a complex and basic element of the device, which determines its technical parameters, the possibility of installation in one place or another, and its geometric dimensions [3].

The wind affects the blades of the generator and this force, or in other words thrust, acts in the direction of the air flow. In turn, a lifting force acts perpendicular to the thrust force, which is exactly what works in wind generators with a horizontal axis of rotation.

In [4], the drag force values were determined as a function of various parameters. A distinctive feature is that the sail blades have small geometric dimensions. 
A known invention [5] aims to increase the windage of the blades and increase the efficiency of using wind energy.

There is also an invention [6], a method and device of Volkov's system to produce energy by the "Parachute capture" method. The method of generating electricity consists in the fact that the rotation of the wind generator blades is carried out due to the wind captured with the help of the concentrator-diffuser system installed on the rotary axis with the ability to rotate in the wind, forming a Laval nozzle in the longitudinal section, in the narrow part of which the wind wheel is installed, and provide creating a lift in the concentrator-diffuser.

The article [7] sets out the foundations of a sailing wind turbine theory. The calculation of a sail-type turbine is presented. The resistance of a blade in the form of a rectangular plate at slight bevel angles $0^{\circ} \leq$ $\mathrm{a} \leq 20^{\circ}$ of a four-blade turbine is determined.

In article [8], the performance coefficients of the sail model and the optimal sail angle are determined based on the results of tests in a wind tunnel.

The authors of [9] provided a detailed overview of the various features of leeward sail flow, including the effect of separation bubbles and vortices at the leading edge.

The authors of this work have developed a sail-type blade of a triangular shape. The developed sail blade presented in this work was tested at speed in the range of $4-12 \mathrm{~m} / \mathrm{s}$.

The purpose of this study is to use wind turbine blades with a dynamically changing shape of surfaces, made in the form of a flexible triangular sail with a movable end, as power elements.

\section{Research methodology}

One of the most important aspects of understanding when learning how a sail works is understanding the acting forces.

The main aerodynamic forces that act on the sail blade during air flow are the lift and drag forces. As shown in Figure 1, these are the perpendicular forces that play a decisive role in the propeller's rotation.

The drag force $\mathrm{F} \mathrm{d}$. is the force parallel to the sail, which is essentially the force that changes the direction of the wind and pushes the propeller sideways.

The lift force F 1 . is the force perpendicular to the sail that provides energy forwards to the sail. Since the lift is directed forward, the wind wheel uses this force to rotate. This is precisely the energy our sailing wind turbine needs to rotate, so it is essential to figure out how to eliminate any other force or circumstance that prevents it.

The resulting force $\mathrm{R}$ is the total component of the aerodynamic forces affecting the sail blade when flowing around with an air stream.

$\alpha$ is the angle of attack, that is, the angle between the jets of the undisturbed incoming flow and the chord (the straight line connecting the extreme points of the sail or fin section).

In order for a lifting force to appear on the sail blade, it should have a given profile and be located to the incoming air stream at a certain angle of attack.

Experiments show that at a certain angle of attack, the boundary layer is separated from the leeward surface of the sail, and with a further increase, an extensive vortex cavity is formed. This is accompanied by a drop in rarefaction and its redistribution along the sail chord; as a result, the lifting force of the sail drops sharply, and the drag increases.

The angle of attack that provides the maximum coefficient of the lift is called the critical angle of attack. This is also called the "stall angle of attack". Below the critical angle of attack, the lift coefficient decreases as the angle of attack decreases. Conversely, above the critical angle of attack, when the angle of attack increases, air begins to flow less smoothly along the upper surface of the profile and begins to separate from the upper surface. With an increase in the attack angle on most profiles, the point of separation of the flow from the upper surface moves from the trailing edge to the leading edge. At a critical angle of attack, the flow on the upper surface is more split and the airfoil or wing provides maximum lift. With a further increase in the angle of attack, the upper surface flow becomes more divided, and the lift coefficient further decreases. 


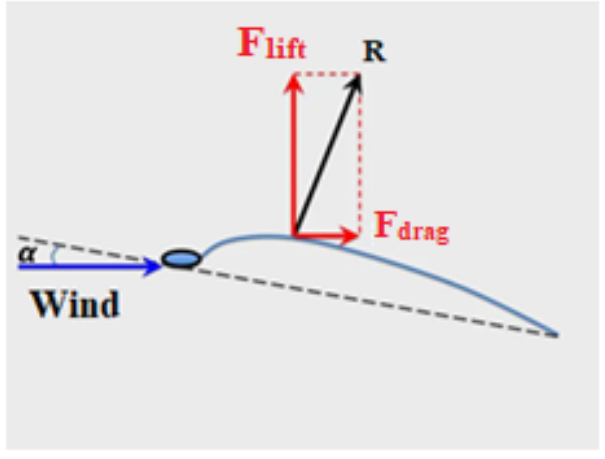

Fig. 1. Location of aerodynamic forces when air flow around the sail blade

Figure 2 shows the mechanism for influencing the air flow on the sail blade, depending on the angle of attack.

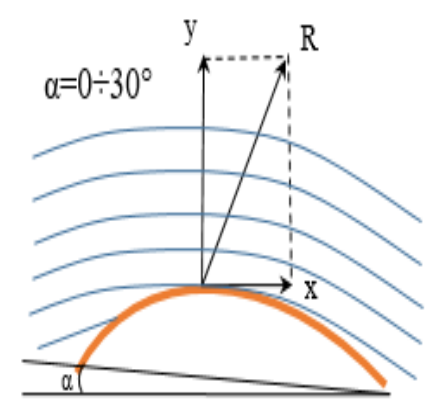

a)

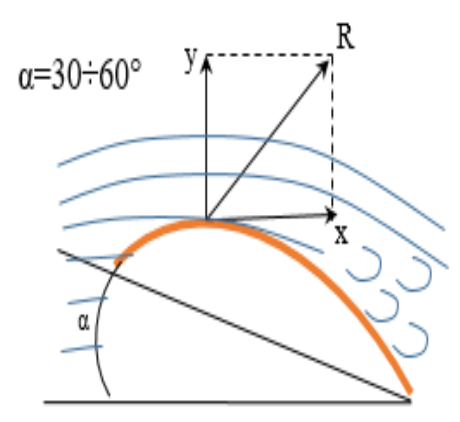

b)

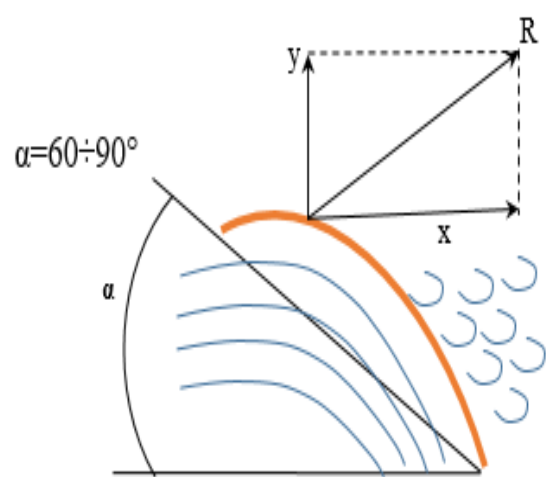

c)

Fig. 2. The location of the sail blade relative to the angle of attack: a) $\alpha=0 \div 30^{\circ}$; b) $\alpha=30 \div 60^{\circ}$; c) $\alpha=60 \div 90^{\circ}$.

As could be seen from the figure, with an increase in the angle of attack from $0^{\circ}-30^{\circ}$, the lift increases sharply, while the drag remains practically at the initial level. In the range of angles of attack of $30^{\circ}-60^{\circ}$, the lift ceases to increase, but the drag force begins to grow strongly, and the resulting total force increases. Finally, at $60^{\circ}-90^{\circ}$, the lift gradually disappears, and the drag increases slightly, reaching a maximum. However, the entire force tends to decrease due to the disappearance of the lifting force.

For the study of aerodynamic forces, a prototype blade with a dynamically changing shape (a sail) was created. The prototype is made of metal frame rods, the material of the triangular sail blade consists of a light and durable material (silk), one end of which is fixed to the top of the frame with a strong thread and support rods and bearing with an inner diameter of $8 \mathrm{~mm}$. Fixed to the rack with support rods.

Several prototypes of elastic, lightweight, and durable blades were tested to create an actual wind turbine design with sailing blades. The material is polyester with a high density, also has a large roughness of the streamlined surfaces. The elasticity and lightness of the raincoat fabric material provide surface flexibility that lends itself well to fluctuations in the air flow, which reduces its resistance. An estimated comparison of the resistance of a solid triangular plate of a similar area showed significantly greater resistance than that of a movable, self-regulating triangular sail shape.

A sail blade differs from other blades in that the sails are made with the ability to change the angle of attack.

Figure 3 shows a prototype of a dynamically variable blade shape. 


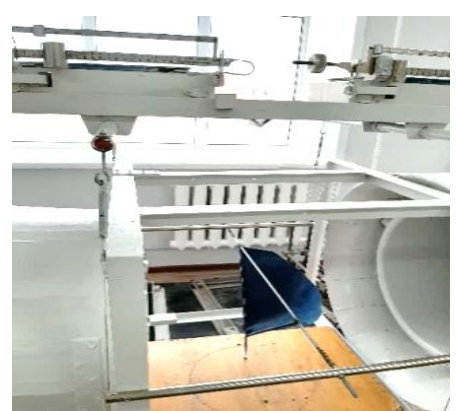

a) layout of the sail blade

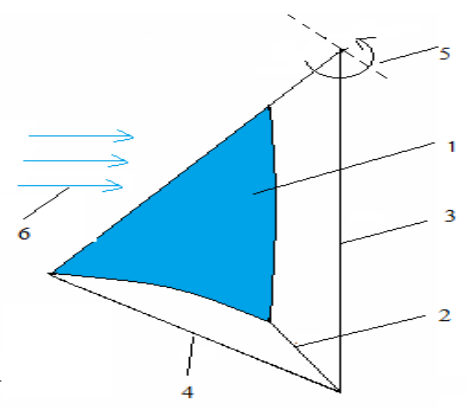

b) blade layout

Fig. 3. Laboratory layout of a sail blade with dynamically variable form:

1 - wind turbine blade with a dynamically variable surface shape, 2,3,4 - frame, 5 - adjustable flexible attachment of the movable end of the blade, made of solid thread, 6 - wind direction

A number of studies have been carried out to determine the aerodynamic characteristics of a prototype sailing blade with a dynamically variable shape. All experimental tests to determine aerodynamic characteristics were carried out in a T - I - M wind tunnel.

In the experiments, the laboratory sample of the blade was airflowed at different speeds. Figure 3 shows the location of the model of the blade sample in the test section of the T-1-M wind tunnel (laboratory of aerodynamic measurements). The flow velocity varied from $3 \mathrm{~m} / \mathrm{s}$ to $12 \mathrm{~m} / \mathrm{s}$.

In the experiments carried out, a three-component aerodynamic balance of the mechanical type was used, Figure 1.

The main units found in all designs of aerodynamic scales are: 1) a supporting device that connects the model installed in the flow to the scales; 2 ) a system of decomposition of the forces and moments perceived by the model into their components; 3) weighing elements for reading measured values; 4) a device for changing the angles of attack and sliding of the model.

The accuracy of determining the aerodynamic coefficients significantly depends on the suspension's design. Therefore, for greater accuracy of measurements made on balance, the design of the supporting devices must meet two conditions:

1) the aerodynamic forces acting on them (primarily the frontal resistance force) should be small compared to the forces acting on the tested model;

2) they should distort the incident flow around the model less.

\section{Research results}

To determine the critical angle of attack, measurements were made of the lift and drag force of the reduced size sail blade on the wind speed.

Figure 4 shows a graph of the drag force dependences and the lift force on the angles of attack of the sail blade at $12 \mathrm{~m} / \mathrm{s}$.

\section{F 1./ F d.}

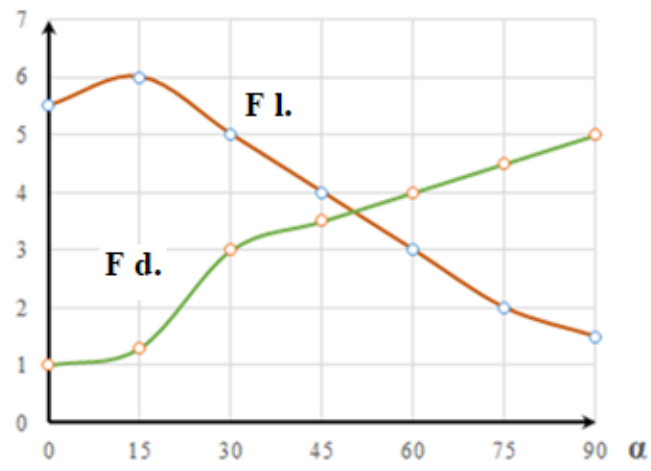

Fig. 4. Dependence of the aerodynamic forces of the sail blade on the angle of attack at $12 \mathrm{~m} / \mathrm{s}$. 
As could be seen from the figure, with an increase in the angle of attack, the sail blade flows around smoothly, the vacuum on the leeward side of the blade increases, and the zone of increased pressure extends from the point of complete deceleration to the entire lower surface of the sail. As a result, the lifting force rises to $6 \mathrm{~N}$.

With an increase in the lifting force, the drag also increases, determined by the frictional force in the boundary layer and the pressure force generated by the pressure difference in front of the sail and behind it. The stream flowing around the sail deflects downward. The greater the angle of attack, the greater the flow deviation. With an increase in the angle of attack to $90^{\circ}$, the boundary layer grows and turbulizes, and the flow begins to stall from the surface of the sail blade. The lift starts to decrease and then drops sharply due to the intense stalling of the flow at an attack angle from 15 to $90^{\circ}$.

At an angle of attack of $15^{\circ}$, the sail blade has a maximum lifting force; therefore, this angle of attack is critical for the sail blade. As the critical angle of attack approaches, the increase in drag accelerates due to the incipient flow stall.

Figures 5 and 6 show the aerodynamic forces at the critical angle of attack of the sail blade.

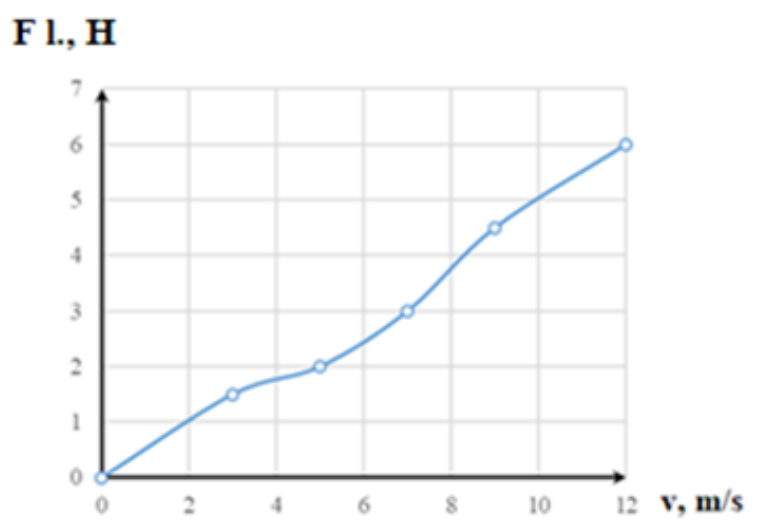

Fig. 5. Graph of the dependence of lift on air velocity

\section{F d., H}

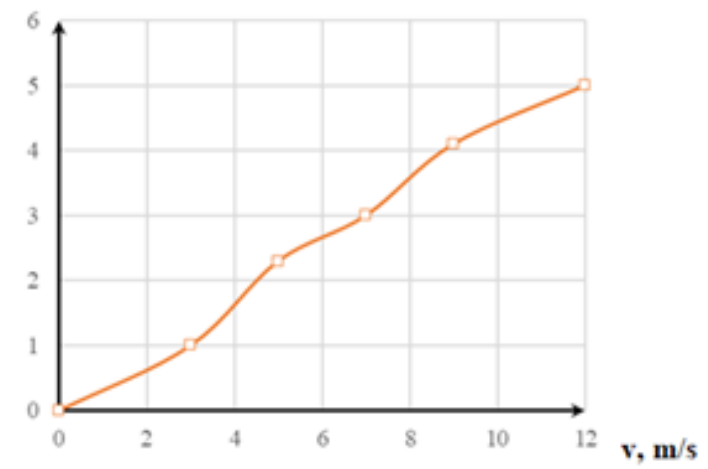

Fig. 6. Graph of the dependence of the drag force on the air flow rate

The obtained dependences show the proportional dependence of the lift force and the drag force of the blades on the flow velocity. The maximum lifting force at an angle of attack of $15^{0}$ is $6 \mathrm{~N}$., and the maximum drag force is about $5 \mathrm{~N}$.

\section{Conclusion}

Based on experimental studies of the aerodynamic forces of a triangular blade of a wind turbine for low wind speeds, the following optimal results were obtained:

- it has been established that the critical angle of attack for a triangular sail blade is $0 \div 15^{0}$, at which the maximum value of the lifting force and the minimum value of the drag force is observed. With a further 
increase in the angle of attack, the lift ceases to increase, but the drag force begins to grow strongly. This phenomenon is explained by the turbulization of the boundary layer.

- the dependences of the aerodynamic forces of the sail blade on the air flow speed at a critical angle of attack of $15^{0}$ were obtained.

- it is determined that the maximum value of the lifting force at an angle of attack of $15^{0}$ is $6 \mathrm{~N}$., as well as the maximum value of the drag force is about $5 \mathrm{~N}$.

\section{REFERENCES}

1 Sakipova S.E., Tanasheva N.K. Modeling aerodynamics of the wind turbine with rotating cylinders. Eurasian Physical Technical Journal. 2019, Vol. 16, No 1(31), pp. 88-93.

2 Kussaiynov K., Sakipova S.Ye., Kambarova Zh.T., Tanasheva N.K., Turgunov M.M., Alibekova A. R., Kusainova A.K. RK Patent No. 30829 F03D 1/00. Published Nov. December 25, 2015. [in Russian]

3 Sakipova S.E., Tanasheva N.K., Minkov L.L. Modeling aerodynamics of a wind turbine with cylindrical blades in a turbulent air flow. Eurasian Physical Technical Journal. 2020, Vol. 17, No 1(33), pp. 106-112.

4 Kambarova Zh.T., Alibekova A.R., Turgunov M.M., Kusaiynov E.K., Ranova G.A. Study of the lab resistance of a triangular blade of a wind turbine for low wind speeds. Tomsk University Bulletin. Series of mathematics and mechanics. 2014, No. 3 (29), pp. 75-81.

5 Dyadchenko N.P. Wind power plant. Patent for invention. Patent number: RU 2625080 C1 Patent office: Russia. Year of publication: 2017; Application number: 2016138908; Date of registration: 03.10.2016; Date of publication: 11.07.2017.

6 Volkov A.E. Method and device of the Volkov system for energy production by the "Parachute capture" method. Patent for invention. Patent number: RU 2348831 C2. Year of publication: 2009.

7 Ershina A.K., Kaptagay G.A. The theory of sailing wind turbines. International Journal of Applied and Fundamental Research. 2011, No. 6, pp. 128-131. https://applied-research.ru/ru/article/view?id=1328

8 Jianhai He, Yihuai Hu, JuanJuan Tang, Shuye Xue. Research on sail aerodynamics performance and sailassisted ship stability. Journal of Wind Engineering and Industrial Aerodynamics. 2015, Vol.146, pp. 81-89.

9 Jean-Baptiste R. G. Souppez; Abel Arredondo-Galeana; Ignazio Maria Viola. Recent Advances in Numerical and Experimental Downwind Sail Aerodynamics. J Sailing Technol. 4 (01): pp. 45-65. Paper Number: SNAME-JST2019-03 https://doi.org/10.5957/jst.2019.4.1.45 